\title{
Educação como prática da liberdade e movimento software livre: produção colaborativa mediada pelas TIC
}

\begin{abstract}
Resumo: Neste texto, mostramos como o modo de produção colaborativo (bazar) do Movimento Software Livre (MSL) se aproxima da Educação como Prática da Liberdade (EPL), principalmente, quando a produção escolar a distância for mediada pelas Tecnologias da Informação e Comunicação (TIC) livres. A participação nas instâncias produtivas do conhecimento potencializa a comunicação e colaboração, tornando as práticas escolares a distância mediadas pelas TIC livres mais participativas, viável-possível e necessária para a inclusão socioeducacional e melhoria na qualidade de vida dos envolvidos.

Palavras-chave: Produção do conhecimento. Pedagogia libertadora. Mediação pedagógica. Movimento Software Livre.
\end{abstract}

\section{Introdução}

Para falarmos das Tecnologias da Informação e Comunicação (TIC) não podemos desvinculá-las dos processos de produção do conhecimento científico-tecnológico, das organizações sociais, da educação em especial. Está cada vez mais evidente que é possível diferenciar, a partir dos modos de produção, as políticas de inclusão socioeducacional a implementar. Neste contexto, as redes passam a ser uma fonte de reorganização das relações de poder e modificam os processos produtivos e culturais. (CASTELLS, 1999) Se por um lado, as forças do mercado têm dominado os fluxos da rede, "[...] utilizando artifícios que retiram e limitam as potencialidades da Internet, seja através de softwares de vigilância, bloqueio e controle, seja por meio de uma legislação." (SILVEIRA, 2000, p. 430) Por outro, a internet é um espaço essencialmente colaborativo, principalmente pelas TIC colaborativas associados a ela e ao contrário das mídias tradicionais, tem na interação a sua alma.

O Movimentos Software Livre (MSL) é a expressão autêntica do potencial colaborativo da internet e o grande modelo para a consolidação de soluções compartilhadas. A partir de um modo de produção centrado na interação e colaboração (produção colaborativa), em A catedral e o bazar, Raymond (1998) faz uma comparação entre dois modos de produção: a) trabalho individual e verticalizado (catedral) e b) trabalho colaborativo e horizontal (bazar). Nos deteremos no modo bazar que é centrado na colabo-

\section{Ilse Abegg}

Professora do Centro de Educação Universidade Federal de Santa Maria iabegg@mail.ufsm.br

Fábio da Purificação de Bastos Professor do Centro de Educação Universidade Federal de Santa Maria fbastos@ce.ufsm.br

Felipe Martins Müller Professor do Centro de Tecnologia Universidade Federal de Santa Maria felipe@inf.ufsm.br 
ração e na interação, tal como em uma feira, porque isso gera um processo educativo e veloz em termos de melhoria do produto a ser desenvolvido e dos seus produtores. Para isso, vamos tomar algumas das lições apresentadas por Raymond (1998) e relacionálas ao trabalho escolar - colaborativo - mediado pelas TIC, em especial pela ferramenta de produção colaborativa wiki, no contexto de Ambientes Virtuais de Ensino-Aprendizagem (AVEA).

Escolhemos o Moodle porque é um software educacional, livre e aberto, para a internet com possibilidades de produção de conteúdos escolares hipermídia, e também porque traz incorporado o wiki como uma ferramenta de atividade. Com isso, não exige a utilização de outra plataforma tecnológica para produção colaborativa e o estudante não necessita sair do AVEA que está sendo mediador do processo de ensino-aprendizagem para colaborar em atividades desta natureza. Assim, os vínculos produtivos entre o modo de produção bazar e a perspectiva da educação como prática da liberdade, mediada pela ferramenta wiki do Moodle, fortaleceram nossas atividades de produção escolar colaborativa.

O termo wiki é utilizado para definir o software colaborativo que cria coleções de páginas interligadas formando um hipertexto ou uma hipermídia. Um software colaborativo é definido como um sistema baseado em computador que auxilia grupos de pessoas envolvidas em tarefas comuns (ou objetivos). Um wiki permite a edição colaborativa de documentos com uma linguagem "simples" e eficaz, por meio de um navegador web, constituindose em verdadeiras mídias hipertextuais, com estrutura de navegação não-linear, onde cada página geralmente contém um grande número de ligações para outras páginas. Trata-se de uma ferramenta, especialmente interessante para atividades de colaboração (trabalhos em grupos) uma vez que permite trabalhar em rede na criação de páginas com um editor html no Moodle. A ferramenta wiki permite um processo comunicativo bidirecional e híbrido, onde todos os envolvidos podem iniciar um tópico de comunicação, rompendo com a hierarquia comunicativa presente em muitas ferramentas.

Dessa forma, as plataformas de produção colaborativa como wikis em AVEA (wiki do Moodle, por exemplo), acrescentam outras perspectivas ao processo de ensino-aprendizagem, proporcionando novas maneiras de realizar as atividades de estudo, 
agregando dimensões como planejamento colaborativo de projetos com aplicações e funcionalidades específicas, nos quais professores e estudantes podem trabalhar em rede, colaborativamente, sobre um tema. (ALBERTI; BASTOS, 2008) Proporciona assim, colaboração e interação na produção escolar (modo bazar).

\section{Lições para a produção colaborativa no modo bazar}

Raymond (1998) apresenta 19 lições mostrando como o trabalho no modo bazar, potencializa a participação nas instâncias comunicativa e colaborativa do processo produtivo. Tomando algumas destas lições, mostramos neste texto, os vínculos produtivos entre o modo de produção do Movimento Software Livre (MSL) e a perspectiva da Educação como Prática da Liberdade (EPL) de Freire, mediada pelas TIC livres, em especial no wiki do Moodle .

Lição 1: Todo bom trabalho começa colocando o "dedo na ferida". Muitas vezes os professores ficam longos anos buscando algo do qual não precisam, ou até nem gostam. Avaliar com cuidado as ferramentas (mediações) à disposição é fundamental e mais ainda, é se perguntar qual delas está mais próxima da necessidade para aquilo que se quer desenvolver. Muitas vezes, reclamamos por não termos um personal computer (pc) para cada estudante, ou não temos acesso a internet (isso é fundamental hoje!), e deixamos de pensar naquilo que realmente podemos fazer. A questão central é: problematizar a educação que estamos praticando cotidianamente, delimitando seus entornos e situações-limite, para num processo de reflexão crítica sobre a prática, ir buscando soluções viáveis-possíveis. (FREIRE, 1983) Dessa forma, muitos dos problemas cotidianos relacionados às ferramentas mediadoras do processo de produção escolar acabam minimizados.

Lição 4: Se você tem a atitude certa, problemas interessantes irão encontrá-lo. Com problematizações interessantes, soluções parciais também o serão, sendo possível e necessário implementar projetos inovadores, mesmo quando não temos todas as ferramentas que julgamos necessárias. Isso é realmente possível, quando temos interesse em participar colaborativamente do projeto em desenvolvimento, pois assim compartilharemos ideias geradoras que podem nos levar à mudanças significativas nas nossas 
atitudes e condutas docentes. Em uma cultura de trabalho colaborativo, atualmente mediado pelos wikis (em nosso caso incorporado no Moodle) isto é um caminho "natural" para um projeto evoluir no âmbito da internet.

Lição 6: Tratar seus usuários (e nós diríamos estudantes) como co-desenvolvedores é seu caminho mais produtivo para uma melhora do código e depuração eficaz. A produção no modo bazar tem como princípio a colaboração, atualmente mediado pelas TIC e ferramentas conectadas, como os wikis. Nesse sentido, a interação professor-estudante precisa ser horizontal, pois com um pouco de estímulo e diálogo todos terão condições de diagnosticar problemas, sugerir soluções e ajudar a melhorar o trabalho educativo de ensino-aprendizagem, principalmente se este for mediado pelas TIC livres como wiki do Moodle. Pois, somente com um método ativo, dialogal e participante poderemos fazê-lo. Segundo Freire (1996, p.116), "[...] quem dialoga, dialoga com alguém sobre alguma coisa. Esta alguma coisa deve ser o conteúdo programático da educação." Neste sentido, o diálogo precisa ser uma interação horizontal de A com B, nascendo de uma matriz crítica e gerando criticidade, sendo assim, um ato comunicativo. (FREIRE, 1996) Nesta mesma perspectiva, o MSL tem no objeto mediador (software livre) a cognoscibilidade para a interação dos sujeitos. Isso melhora muito nosso ensino-aprendizagem, quando vivida na mesma perspectiva colaborativa da comunidade do MSL, na qual o modelo de desenvolvimento e produção do conhecimento está centrada na interação dialógico-problematizadora, entre professor e estudante, mediados pelos objetos de estudo (conhecimento) e suas respectivas ferramentas didáticas (materiais didáticos). Pois a ação docente não se faz sem a ação discente e, assim como o "desenvolvedor-usuário" vai assumindo a autoria e reconhecendo-se como "co-desenvolvedor" o estudante vai aprendendo-ensinando, tornando-se educando-educador e coautor de sua própria aprendizagem. (FREIRE, 1997)

Lição 7: Libere cedo. Libere frequentemente. E ouça seus fregueses. Assim como o modelo de produção "bazar", o processo educativo também precisa compartilhar o planejamento antes mesmo do momento da ação, oferecendo a oportunidade para que todos possam contribuir. Essa é uma boa maneira de ouvir os estudantes! Isso nada mais é do que um processo de investigação-ação escolar, no qual os passos cíclicos-espiralados de investigação inicial, pla- 
nejamento, ação e reflexão alcançam a melhora do desenvolvimento e cultiva a colaboração como essência. Manter todos constantemente estimulados e recompensados - "estimulados pela perspectiva de estar tendo um pouco de ação satisfatória, recompensados pela visão do constante melhoramento do seu trabalho", ou seja, participação ativa dos envolvidos, caracteriza o modo de produção colaborativa no processo educativo num movimento de problematização dialógico. Trata-se de assumir empaticamente a interação colaborativa e acreditar na potencialidade ontológica do ser mais, em especial dos nossos estudantes, que participam ativamente do ensinar-aprender cotidiano.

Lição 8: Dada uma base grande o suficiente de beta-testers e codesenvolvedores, praticamente todo problema será caracterizado rapidamente e a solução será óbvia para alguém. A "lei de Linus" diz que: "dado olhos suficientes, todos os erros são triviais", ou seja, todo problema será transparente para alguém! Para o estilo bazar de produção quem "acha" o problema não necessariamente é quem o melhor entende e pensa a melhor solução (teórica) para o momento. Isso na prática pode vir ainda de outra pessoa, envolvida no processo é claro, como os estudantes nas aulas, mas que na maioria das vezes os admitimos num nível cognitivo inferior. Isso em termos educativos significa dizer que os problemas da prática educativa podem tornar-se "triviais" quando expostos para um grupo de ávidos colaboradores como nossos estudantes. O compartilhamento do planejamento passa pelo compartilhamento dos resultados esperados da ação, e isso requer uma comunicação entre os envolvidos, ou seja, um diálogo aberto sem constrangimentos, essencial na investigação-ação escolar. É assim que se constituem colaborativamente as comunidades, onde mais participantes acham mais erros porque ao interagir, adicionam mais maneiras diferentes de testar seus produtos (softwares 1ivres). Este efeito é amplificado quando os participantes têm condutas de investigadores ativos-críticos, pois cada um vê um problema, propondo tarefa de um ponto de vista diverso, pois tem um ângulo diferente sobre o mesmo. Esta diversidade também é fundamental para o desenvolvimento do trabalho colaborativo escolar mediado pelas TIC livres, em especial pelo wiki incorporado no Moodle.

Lição 11: A melhor coisa depois de ter boas ideias é reconhecer boas ideias dos seus usuários [estudantes]. Valorizar o conhecimento 
prévio do estudante é fundamental para problematizar temáticas no campo da ciência e tecnologia, estabelecendo interfaces entre a realidade vivida e os conceitos científico-tecnológicos. É nestes momentos de diálogo-problematizador que o professor muitas vezes encontra a melhor solução para determinado problema, e descobre que a solução planejada anteriormente não é mais a melhor. Em outras palavras, quando a validação do trabalho passa pela via dialógica, potencializa-se a colaboração dos estudantes e assumese que os mesmos são valiosos para o desenvolvimento do ensinoaprendizagem e portanto, para a ação docente.

Lição 14: Qualquer ferramenta deve ser útil da maneira esperada, mas uma ferramenta verdadeiramente "boa" leva ela própria a usos que você nunca esperou. As ferramentas e objetos de ensinoaprendizagem precisam ser abertas, para proporcionar um certo "estado de inacabamento" (próprio do conhecimento científicotecnológico). Professor e estudantes precisam executar, estudar, aperfeiçoar e redistribuir, dando outras funcionalidades, que nem sempre quem elaborou pensou. Muitas ferramentas acabam não sendo objeto mediador da prática docente diária, porque elas não podem ser customizadas para uma dada realizada. Consequentemente, o manuseio reflexivo ganha bom potencial para gerar inovações, daí nossa argumentação a favor de mediação tecnológica livre, pois isso pode levar a desenvolvimentos não esperados inicialmente.

Lição 18: Para resolver um problema interessante, comece achando um problema que é interessante para você. Os grandes projetos educativos começam como soluções pessoais para os problemas diários que, se espalham porque se tornam comum para um grande número de pessoas. Ou seja, num processo de InvestigaçãoAção Escolar (IAE) ao compartilharmos um problema, inicialmente julgado como particular, podemos descobrir ser comunitário e pode ser problematizado colaborativamente (momento do planejamento). Para Membiela (2002, p. 444), "[...] a IAE está interessada nos problemas práticos que os professores encontram nas aulas e a encontrar soluções para os mesmos. Isso implica no desenvolvimento profissional dos professores." O MSL está nesta mesma perspectiva, pois ao se programar um software este precisa ter uma evolução na presença de uma comunidade (como a do Moodle e do wiki, por exemplo) de co-desenvolvedores. Assim como num projeto de IAE, quando compartilhamos um 
problema se encoraja outras pessoas a procurar erros e as melhorias potenciais acontecem drasticamente mais rápidas que em qualquer outro lugar. Raymond (1998, p. 10) afirma que no MSL, "[...] o desenvolvedor não trabalha sozinho em um projeto fechado, se fizer isso, ficará atrás de desenvolvedores que saibam como criar um contexto aberto e evolutivo no qual a visualização de erros e melhorias sejam feitas por centenas de pessoas...[...] ."

Segundo o autor, não é uma coincidência que o GNU-Linux tenha sido gestado junto com o nascimento da World Wide Web, por exemplo. Por isso também, os projetos educativos atuais não podem abrir mão do trabalho colaborativo mediado pelas TIC livres, em especial pela ferramenta wiki no Moodle. Outros fatores vitais aproximam o MSL da EPL num processo de IAE: esses necessitam de um estilo de liderança (condução) e conjunto de formalidades cooperativas (procedimentos metodológicos). No projeto GNU-Linux, isso permitiu aos desenvolvedores atrair codesenvolvedores e obter o máximo suporte da plataforma de trabalho. Mas tanto no MSL quanto na EPL e IAE, este estilo de liderança e tais formalidades não podem estar baseados em relações de poder ("princípio de comando e disciplina"), mas sim numa conduta dialógico-problematizadora ("princípio da compreensão comum"). Em ambas modalidades de produção colaborativa (modo bazar), o objetivo só poder ser atingido pelo "esforço severo de muitos propósitos convergentes".

Esta perspectiva é o que Raymond (1998, p.12) chama de "Lei de Linus", que pode ser entendida como "[...] uma maneira de criar um mercado eficiente para ligar a autonomia de desenvolvedores individuais tão firme quanto possível para dificultar fins que podem ser somente atingidos por uma cooperação sustentada." É neste sentido que a mediação das TIC livres torna-se fundamental, em especial no Moodle, que disponibiliza ferramentas de atividades colaborativas (wiki por exemplo), potencializando benefícios de se ter uma comunidade trabalhando num projeto de forma organizada e orientada. Logo, a mediação das TIC livres em tempos de produção na internet, torna-se fundamental para o trabalho colaborativo, dialógico e valorização dos parceiros!

Lição 19: Contanto que o coordenador do desenvolvimento tenha uma mídia tão boa quanto a internet, e saiba como liderar sem coerção, muitas cabeças são inevitavelmente melhores que uma. O tra- 
balho educacional colaborativo tende a triunfar em tempos de internet, pois gradativamente as pessoas envolvidas (estudantes e professores) estão deixando para trás o modelo "catedral" de produção e abraçando o modo "bazar". Podemos ver isso, nas políticas públicas científico-tecnológicas (concretizadas nos incentivos financeiros disponibilizados pelos órgãos públicos), que fomentam pesquisa no país, onde cada vez mais coloca-se como critérios: a parceria e colaboração; a formação de equipes multidisciplinares; o trabalho colaborativo entre os pesquisadores das universidades e professores e estudantes da educação básica. Também em educação precisamos "abrir os códigos" e trabalharmos mais colaborativamente, produzindo objetos livres para serem executados, estudados, adaptados e redistribuídos em todas as esferas educativas.

Assim, os processos ligados à produção do conhecimento escolar passam a exigir colaboração como essencialidade. Se o conhecimento é visto como uma construção social e vinculado à participação humana, sua evolução depende do trabalho colaborativo e não individual. Para tanto, fazem-se necessárias atitudes e condutas permeadas por um senso de colaboração que, por si só, baseia no construto coletivo para a formação do produto final a partir de mudanças de valores entre o público e o privado. Portanto, o foco passa a ser "no nosso." (SCHONS, 2008) Esta mesma abordagem é dada por Lèvy (1998 apud SCHONS, 2008, p. 82) quando discute o conceito de "inteligência coletiva", defendendo que "Ninguém sabe tudo, todos sabem alguma coisa, todo o saber está na humanidade." Ideia que também está de acordo com o pensamento freireano ao dizer que "ninguém educa ninguém, todos se educam em comunhão." Ou seja: "[...] nas condições de verdadeira aprendizagem os educandos vão se transformando em reais sujeitos da construção e da reconstrução do saber ensinado, ao lado do educador, igualmente sujeito do processo." (FREIRE, 1997, p. 29) Por isso, a colaboração no processo ensino-aprendizagem torna-se fundamental, ainda mais quando esta é mediada por TIC livres (com a proposição de atividades educacionais mediadas por ferramentas de produção colaborativas como o wiki do Moodle, por exemplo).

Contudo, planejar atividades de estudo centradas no diálogo, na problematização de situações-problema e na participação ativa dos estudantes, sob a orientação do professor, é fundamen- 
tal para alavancar a produção colaborativa no âmbito escolar (modo bazar). Para isso, o professor precisa acompanhar o desenvolvimento dos estudantes, propor novas atividades e espaços de interação para concretizar a produção colaborativa, essencial para o Ser Mais. Neste sentido, atividades wikis potencializam a superação de práticas "usuárias" e "consumistas" de ideias. Ao se dispor ao diálogo-problematizador, os estudantes têm a oportunidade de se constituírem "intérpretes-autores" desencadeando um processo colaborativo de produção escolar.

\section{Educação como prática da liberdade e movimento software livre: participação nas instâncias produtivas das TIC}

A perspectiva de produção colaborativa do MSL e da EPL proporciona aos envolvidos a oportunidade de "liberdade de produção" e, consequentemente, de desenvolvimento da autonomia, ou seja, da tomada de decisão. A expressão livre em "software livre" precisa ser entendida como "liberdade de produção" e aqui está a maior interface com a EPL, pois esta tem por base a liberdade cultural, condição necessária para a colaboração e o desenvolvimento da autonomia. Somente na sociedade é que somos livres, pois é na interação com o outro que construímos a liberdade, vivendo duas das quatro liberdades do MSL (a $\mathrm{n}^{\circ} 2$ garante a liberdade de redistribuir cópias de modo que você possa ajudar ao seu próximo e a $\mathrm{n}^{\circ} 3$, a liberdade de aperfeiçoar o programa e liberar seus códigos aperfeiçoados ao público, de modo que toda a comunidade se beneficie). Portanto, essas duas liberdades estão diretamente relacionadas com a EPL, prevendo interação dialógica com o outro, redistribuindo algo, antes ou depois de aperfeiçoado, que só tem sentido, se para quem está recebendo uma cópia esta lhe será útil. E nós só saberemos disso se compartilharmos nossos quefazeres educacionais (problemas e soluções) com o outro numa interação dialógico-problematizadora.

A construção da liberdade também está na interação educador-educando, segundo a EPL, não pode ser o ato de depositar, narrar ou de transferir conhecimentos aos educandos como meros "consumidores" a base desta interação. A EPL coloca a exigência da superação da contradição educador-educando, e destaca a interação dialógica, indispensável na colaboração e desenvolvi- 
mento da autonomia e, consequentemente, da liberdade. Segundo Freire (1997), é preciso que o educando vá assumindo o papel de sujeito da produção, reconhecendo-se como arquiteto de sua própria prática cognoscitiva. "O ensino de conteúdos demanda que quem se acha na condição de aprendiz, vá assumindo a autoria também do conhecimento do objeto." (FREIRE, 1997, p. 140) Assim, o MSL coloca em prática a EPL, em que o objeto mediador (Software Livre) torna-se essencial para a cooperação e colaboração entre os sujeitos, porque tem como princípio a produção colaborativa. Pode-se dizer que a interação desenvolvedor-usuário está na mesma instância do educador-educando, pois para o MSL é imprescindível que o usuário vá assumindo a autoria e reconhecendo-se como codesenvolvedor.

As liberdades de executar, estudar, redistribuir e aperfeiçoar do MSL têm na acessibilidade do código fonte, a condição necessária para ser livre. Para que essas liberdades sejam reais, elas precisam ser irrevogáveis, por isso, temos que ter políticas públicas científico-tecnológicas bem delineadas que assegurem acesso aos meios de produção dos mais diversos objetos tecnológicos que mediam o processo educativo, como é o caso do wiki do Moodle, por exemplo. Assim, poderíamos consolidar um modo de produção que tem como princípio a colaboração na produção de bens comuns e o resultado desta, torna-se propriedade de todos, sem restrições de acesso. Segundo Silveira (2008, p. 438),

[...] o movimento de software livre é a maior expressão da imaginação dissidente de uma sociedade que busca mais do que a sua mercantilização. Trata-se de um movimento com base no princípio do compartilhamento do conhecimento e na solidariedade praticada pela inteligência coletiva conectada na rede mundial de computadores.

No âmbito educacional o processo colaborativo também é fundamental, pois é por meio de ações colaborativas que construímos uma sociedade mais justa, e, acima de tudo, é a maneira viável-possível de desenvolver a autonomia. Atualmente, não podemos mais falar em ação colaborativa e desenvolvimento da autonomia sem falarmos da integração das TIC livres no processo escolar. Os grandes projetos e experiências de "infoinclusão" no Brasil, defendem o computador como ferramenta para a trans- 
formação social sem ser um fim em si mesmo. Quando unimos infoinclusão e software livre, esta se torna "a melhor alternativa" porque o "[...] software vem acompanhado de um movimento de libertação, de emancipação, de geração de autonomia tecnológica." (ALENCAR, 2007, p. 80)

Autores como Cabral (2008) e Sampaio (2008), acreditam que incluir esta perspectiva tecnológica envolve "apreender o discurso da tecnologia" e não apenas os comandos de determinados programas para a execução de determinados fins. Além de qualificar as pessoas para o mundo do trabalho, é preciso capacidade para influir na decisão sobre as finalidades da tecnologia digital. Isso para Cabral (2008) está diretamente relacionada a uma perspectiva de inclusão educacional, de política pública e de construção de cidadania. Para Sampaio (2003 apud CABRAL, 2008, p. 3), o papel das TIC é

[...] fomentar o exercício da cidadania, para dar voz as comunidades e setores que normalmente não têm acesso à grande mídia e para apoiar a organização e o adensamento da malha de relações comunicativas entre os autores da sociedade civil que constituem a Esfera Pública.

Esta perspectiva está de acordo com as ideias propostas no documento da I Oficina de Inclusão Digital, o qual defende que "[...] a formação de educadores deve garantir que eles não sejam simplesmente consumidores de informações, bens e serviços, mas também produtores de cultura e conhecimento." (BRASIL, 2001, p. 10) Para isso, a formação de professores precisa centrar-se, necessariamente, nos conhecimentos científico-tecnológicos que envolvem as TIC livres que mediam a produção do conhecimento escolar. Assim, os profissionais da educação teriam uma formação na perspectiva da inclusão, pois: "Inclusão Digital não é apenas o ensino de informática na escola, muito menos se restringe ao simples acesso a computadores. Envolve a tarefa de repensar a inserção das TIC no processo de construção de conhecimento através de acesso, colaboração, comunicação, representação e autoria. (BRASIL, 2001, p. 6)

Assim, as TIC precisam ser utilizadas para integrar a escola e a comunidade, de maneira que a educação mobilize rumo à sistematização e racionalidade emancipatória, em todas as instâncias, do trabalho ao papel(ação) de cidadão na sociedade. Para isso, o conhecimento precisa ser a ferramenta básica para o desenvol- 
vimento. Neste contexto, o conceito de software livre se insere no sentido que pretende impedir a exploração permanente e desmedida em torno do conhecimento que se produz. Em termos de Educação como Prática da Liberdade, acreditamos ser este o caminho viável-possível, pois esta perspectiva busca uma formação para além do uso das TIC, onde os envolvidos precisam participar do processo de planejamento e produção dos meios que produzem a sociedade.

Neste sentido, se implementarmos atividades de estudo mediadas por wikis, principalmente em AVEA como é o caso do wiki do Moodle, possibilitaremos uma produção colaborativa do conhecimento escolar (modo bazar). Pois, o wiki do Moodle é uma ferramenta de atividade que permite a produção de hipermídia educacionais reestruturando o conhecimento como resposta às demandas situacionais. Além de compartilhar e distribuir o conhecimento, os produtos produzidos podem ser revisitados pelos estudantes sempre que necessário.

Produzir com os estudantes, colaborativa e hipermidiaticamente, o conhecimento escolar mediados pelo wiki do Moodle, constitui uma maneira de participar da produção rompendo com a situação de "consumidor" de informações. Ao tomar como princípios os fundamentos da EPL e do MSL, proporcionamos aos envolvidos vivências essenciais como: construção colaborativa do conhecimento escolar; múltiplas representações dos conceitos, leis e fenômenos envolvidos nos problemas abordados possibilitando avaliar soluções e decisões na perspectiva do diálogo-problematizador; apropriar-se do processo de produção da aprendizagem colaborativa juntamente com o professor que orienta a organização dos percursos produtivos; envolver-se no processo de conscientização e construção de conhecimento escolar compreendendo como se aprende colaborativamente. Assim, torna-se possível decidir e se capacitar para dialogar sobre como uma determinada atividade foi resolvida de forma aberta, isto é, com conduta reflexiva-ativa, mediada pelos conceitos científico-tecnológicos.

\section{Considerações finais}

A incorporação das TIC nas práticas educativas está bem acentuada, principalmente, no Moodle que vem mediando praticamen- 
te todas as modalidades educacionais (presencial, semipresencial e a distância) nas universidades públicas brasileiras. A educação como processo de construção humana do sujeito social, autônomo, criativo e participativo emerge do ensinar-aprender. Mediada pelas tecnologias educacionais como o Moodle e sua ferramenta de atividade colaborativa wiki, potencializam a produção escolar de forma dialógico-problematizadora e colaborativa, portanto concretizando o modo de produção bazar na instância educativa.

Para problematizar ensino-aprendizagem científicotecnológico, precisamos mudar os processos comunicativos estabelecidos na interação educacional mediada por ferramentas de atividades e o professor precisa proporcionar aos estudantes situações-problema para desenvolver condutas dialógicoproblematizadoras na perspectiva da conscientização. Isso torna-se viável-possível e potencializador da construção da autonomia dos sujeitos envolvidos nesta ação cultural, proporcionando um processo comunicativo e fluência científico-tecnológica.

Segundo Freire (1996, p. 35), "[...] o respeito à autonomia e à dignidade de cada um é um imperativo ético e não um favor que podemos ou não conceder uns aos outros." Para isso, o professor precisa desenvolver habilidades de investigação e permitir que o outro atue com a sua singularidade, construindo-se sujeito da sua própria aprendizagem. Além disso, o diálogo é condição imprescindível, pois, segundo Freire (1997), somente na interação dialógica, que implica num pensar crítico, somos capazes, de gerar educação. Sem ele, não há comunicação e, consequentemente, não há verdadeira educação dialógico-problematizadora, como prática da liberdade, mesmo que seja a distância mediada pelas TIC livres, como o wiki do Moodle.

O processo dialógico-problematizador no ensino-aprendizagem produz autonomia, mas exige colaboração ativa entre os sujeitos e ocorre nas situações de comunicação. Esta ideia é central na perspectiva da EPL e MSL, onde

[...] a co-laboração, como característica da ação dialógica, que não pode dar-se a não ser entre sujeitos, ainda que tenham níveis distintos de função, portanto, de responsabilidade, somente pode realizar-se na comunicação. O diálogo, que é sempre comunicação, funda a co-laboração. (FREIRE, 1997, p. 104) 
Por isso, apostamos que atividades de estudo mediada pela ferramenta de atividade wiki do Moodle, fundada no diálogoproblematizador e no modo bazar de produção, potencializa a autonomia dos envolvidos, os quais vão se construindo sujeitos coautores de seus próprios quefazeres de ensino-aprendizagem.

Education as Practice of Freedom and Free Software Movement: collaborative production mediated by ICT

\begin{abstract}
In this paper, we show how the collaborative production (bazaar) of the Free Software Movement is close Education as the Practice of Freedom, especially when the distance teaching is mediated by free Information and Communication Technologies (ICT). Participation in school productive enhances the communication and collaboration, making the practices the distance mediated by free ICT more participatory, feasible, possible and necessary to include educational and improvement in quality of life of those involved.
\end{abstract}

Keywords: Production of knowledge. Liberating pedagogy. Pedagogical mediation. Free Software Movement.

\title{
Referências
}

ALBERTI, T. F.; BASTOS, F. da P. de. A teoria da atividade como orientação psicopedagógica na implementação de atividades de estudo em ambientes virtuais. Ciências \& Cognição, v. 13, n. 2, p. 243-257, 2008. Disponível em: <http://www.cienciasecognicao.org >. Acesso em: 13 set. 2008

ALENCAR, A. F. A pedagogia da migração do software proprietário para o livre: uma perspectiva freiriana. Dissertação (Mestrado) - Faculdade de Educação, Universidade de São Paulo, São Paulo, 2007.

BRASIL. I OFICINA DE INCLUSÃO DIGITAL, 2001. In: NAZARENO, C. et al. Tecnologias da informação e sociedade: o panorama brasileiro. Brasília, DF.: Câmara dos Deputados, Coordenação de Publicações, 2006.

CABRAL, A. Sociedade e tecnologia digital: entre incluir ou ser incluída. [2008] Disponível em: <http://www.comunicacao.pro.br/ artcon/includig.htm >. Acesso em: 10 jul. 2008.

CASTElls, M. A sociedade em rede. São Paulo: Paz e Terra, 1999.

FREIRE, P. Pedagogia da autonomia: saberes necessários à prática educativa. 15. ed. São Paulo: Paz e Terra, 1996.

1983.

Pedagogia do oprimido. 13. ed. Rio de Janeiro: Paz e Terra,

Educação como prática da liberdade. 22. ed. Rio de Janeiro:

Paz e Terra, 1997. 
MEMBIELA, P. Investigación-acción en el desarrollo de proyectos curriculares innovadores de ciencias. Enseñanza de las Ciencias, v. 20, n. 3, p. 443-450, 2002.

RAYMOND, E. S. A catedral e o bazar. 1998. Disponível em: < www.dominiopublico.gov.br/download/texto/t1000001.pdf > Acesso em: 10 maio 2002.

SAMPAIO, J. T. O que é inclusão digital? [2008] Disponível em: <http://www.sampa.org >. Acesso em: 19 jul. 2008.

SCHONS, C. H. A contribuição dos wikis como ferramentas de colaboração no suporte à gestão do conhecimento organizacional. Informação \& Sociedade: Estudos, João Pessoa, v. 18, n. 2, p. 79-91, maio/ago. 2008. Disponível em: <http://www.ies.ufpb.br/ojs2/ index.php/ies/article/view/1706 > . Acesso em: 16 out. 2008.

SILVEIRA, S. A. O conceito de commons na cibercultura. Líbero, Ano 11, n. 21, p. 49-59, jun. 2008.

SILVEIRA, S. A. da. Inclusão digital, software livre e globalização contra-hegemônica: seminários temáticos para a $3^{\text {a }}$ Conferência Nacional de CT\&I. 2000. < http://www.softwarelivre.gov.br/

softwarelivre/artigos/artigo_02 >. Acesso em: 14 jul. 2008. 
